\title{
Análise das Estratégias de Escrita de Crianças Pré-Escolares em Português do Brasil
}

\author{
Renan de Almeida Sargiani \\ Universidade de São Paulo - São Paulo - Brasil \\ Ana Albuquerque \\ Universidade de São Paulo - São Paulo - Brasil
}

\begin{abstract}
Resumo
Neste estudo tivemos três objetivos: 1) investigar as estratégias que pré-escolares usam para escrever palavras em português do Brasil; 2) analisar os diferentes tipos de escrita e de letras usadas; e 3) criar critérios explícitos para classificar as escritas das crianças e servir como parâmetros para pesquisas e práticas pedagógicas. Os participantes foram 38 crianças com idade média de 70.3 meses. As crianças foram avaliadas por um ditado de 15 palavras e tarefas de conhecimento de letras, consciência fonológica (silábica e fonêmica) e inteligência não-verbal. As escritas foram digitadas e analisadas de acordo com critérios elaborados com base nas estratégias de escrita observadas. Os resultados mostraram que a maioria das crianças utilizou predominantemente estratégias alfabéticas parciais, que refletem a aquisição e o uso do conhecimento de letras e da consciência fonêmica.
\end{abstract}

Palavras-chave: Linguagem escrita; ortografia; alfabetização.

\section{Analysis of Preschool Children's Spelling Strategies in Brazilian Portuguese}

\begin{abstract}
In this study we had three objectives: 1) to investigate the strategies preschoolers use to write words in Brazilian Portuguese; 2) analyze the different types of writing and letters used; And 3) create explicit criteria for classifying children's writing and it could serve as parameters for research and pedagogical practices. The participants were 38 children with mean age of 70.3 months. The children were evaluated by a dictation of 15 words and tasks of letter knowledge, phonological awareness (syllabic and phonemic) and nonverbal intelligence. The writings were typed and analyzed according to criteria elaborated based on the writing strategies observed. The results showed that most children predominantly used partial alphabet strategies, which reflect the acquisition and use of letter knowledge and phonemic awareness.
\end{abstract}

Keywords: Written language; spelling; literacy.

\section{Análisis de las Estrategias de Escritura de Niños Preescolares en portugués de Brasil}

\section{Resumen}

En este estudio tuvimos tres objetivos: 1) investigar las estrategias que preescolares usan para escribir palabras en portugués de Brasil; 2) analizar los diferentes tipos de escritura y de letras usadas; y 3) crear criterios explícitos para clasificar las escrituras de los niños y servir como parámetros para investigaciones y prácticas pedagógicas. Los participantes fueron 38 niños con edad media de 70.3 meses. Los niños fueron evaluados por un dictado de 15 palabras y tareas de conocimiento de letras, consciencia fonológica (silábica yfonética) e inteligencia no-verbal. Las escrituras fueron digitadas y analizadas de acuerdo con criterios elaborados con base en las estrategias de escritura observadas. Los resultados enseñaron que la mayoría de los niños utilizó predominantemente estrategias alfabéticas parciales, que reflejan la adquisición y el uso del conocimiento de letras y de la consciencia fonética.

Palabras clave: Lenguaje escrita; ortografía; alfabetización. 


\section{Introdução}

Para ler e escrever em sistemas alfabéticos de escrita (como é o caso do português, inglês e espanhol), os aprendizes têm que compreender que grafemas (letras) nas grafias representam fonemas (sons) nas pronúncias (Byrne \& Fielding-Barnsley, 1990; Rayner, Foorman, Perfetti, Pesetsky, \& Seidenberg, 2001) Durante o desenvolvimento da linguagem escrita, observam-se diferentes estratégias utilizadas pelos aprendizes, que demonstram suas tentativas de dominar o sistema alfabético. Buscando identificar padrões desenvolvimentais e explicar os mecanismos envolvidos na aquisição da leitura e da escrita,teóricos em Psicologia do Desenvolvimento e da Aprendizagem propuseram diferentes modelos de desenvolvimento da linguagem escrita com explicações por vezes contraditórias (Ehri, 2005b, 2014; Ferreiro \& Teberosky, 1999; Pollo, Treiman, \& Kessler, 2015) Com base em convergências desses modelos, neste estudo objetivou-se examinar as estratégias que crianças pré-escolares falantes de português do Brasil utilizam para escrever palavras.

Uma teoria sobre o desenvolvimento da linguagem escrita com grande influência na América Latina é a chamada Psicogênese da Língua Escrita de Emília Ferreiro, que conduziu a maior parte de seus estudos com falantes de espanhol (Ferreiro \& Teberosky, 1999; Ferreiro, 1990; Vernon \& Ferreiro, 1999). Ferreiro foi particularmente influente por estender a abordagem piagetiana do desenvolvimento cognitivo para o desenvolvimento da linguagem escrita (teoria construtivista), propondo que as crianças, ao refletirem sobre a linguagem escrita presente ao seu redor, constroem hipóteses conceituais sobre como a escrita funciona (Ferreiro \& Teberosky, 1999).

Na teoria psicogenética, o desenvolvimento da linguagem escrita equivale a mudanças nas hipóteses conceituais que as crianças constroem, passando por quatro estágios com características específicas: pré-silábico, silábico, silábico-alfabético e alfabético. Para Ferreiro (1999),o desenvolvimento ocorre por mudanças qualitativas nas hipóteses predominantes que caracterizam cada estágio. As crianças permanecem durante certo tempo em um estágio governado por uma hipótese mais rudimentar até que mudam em direção a uma hipótese mais evoluída.

O primeiro estágio é denominado pré-silábico, no qual as crianças têm pouco conhecimento sobre o sistema de escrita e suas hipóteses são bastante simples e distantes do real funcionamento do sistema alfabético de escrita (e.g. usam letras aleatórias). O segundo estágio é o silábico e é caracterizado pela hipótese de que, para escrever palavras, deve ser usada uma letra para representar cada sílaba (ex. AAO para CAVALO); pode ser divido em dois sub-estágios: 1) silábico sem valor sonoro: uma letra para cada sílaba ainda que sem correspondência sonora (ex. VB para CASA); e 2) silábico com valor sonoro: uma letra para cada sílaba com correspondência sonora (ex. AA para CASA). No estágio seguinte, silábico-alfabético, as crianças passam a usar mais letras para escrever palavras, mas não todas. 0 estágio alfabético é o último e é quando surgem as escritas convencionais (Ferreiro \& Teberosky, 1999).

A existência de uma hipótese silábica no desenvolvimento da escrita tal como proposta por Ferreiro é questionada por diversos autores (Cardoso-Martins \& Corrêa, 2008; Cardoso-Martins, 2013; Kamii, Long, Manning, \& Manning, 1990; Pollo \& cols., 2015; Treiman, Pollo, Cardoso-Martins, \& Kessler, 2013). Kamii e cols. (1990), em um estudo comparando crianças falantes do inglês e do espanhol, não encontraram evidências para um estágio silábico entre crianças que falam inglês. Identificaram o denominado estágio consonântico para o uso exclusivo de consonantes.

Ferreiro (1990) afirmou que as escritas silábicas são raras ou ausentes em inglês porque esse sistema tem mais palavras monossilábicas do que outras línguas como o espanhol. Tal afirmação sugere que as escritas silábicas são um fenômeno significativo para línguas românicas, em que a estrutura silábica é mais evidente. De fato, a maioria das evidências em favor da existência de um estágio silábico no desenvolvimento da escrita são oriundas de estudos conduzidos em línguas românicas e em crianças de 4 e 5 anos: italiano (Pontecorvo \& Zucchermaglio, 1988), português europeu (Alves-Martins \& Silva, 2006) e espanhol (Ferreiro \& Teberosky, 1999). Entretanto, Cardoso-Martins forneceu evidências em vários estudos com crianças falantes do Português do Brasil, que questionam a existência de um estágio silábico e a primazia deste na compreensão do sistema alfabético (Cardoso-Martins \&Batista, 2005; Cardoso-Martins \& Corrêa, 2008; Cardoso-Martins, 2013; Kessler, Pollo, Treiman, \& Cardoso-Martins, 2013).

Treiman e cols. (2013) testaram a frequência de ocorrência de escritas silábicas em Português do Brasil. Os dados revelaram que a maioria das crianças produziu algumas escritas nas quais o número de letras combinava com o número de sílabas, porém poucas crianças produziram significativamente mais escritas do que esperado ao nível do acaso. Cardoso-Martins e Batista (2005) propuseram que a escrita silábica é o resultado da compreensão de que as letras representam pequenos segmentos sonoros e da tentativa de representar os sons que detectam na pronúncia das palavras. As crianças se beneficiam, especialmente, dos nomes das letras para representar os sons das palavras (e.g., em CABELO, a grafia KBO pode incluir implicitamente os nomes das letras K, cá, e B, bê).

O conjunto de evidências apresentado por Cardoso-Martins (2013) sugere que não necessariamente as crianças brasileiras passem por um estágio silábico. Também identificou que a teoria proposta por Linnea Ehri (1992, 1998, 2005a, 2005b, 2014), baseada em evidências de falantes do inglês, parece mais apropriada para explicar o desenvolvimento da linguagem escrita em português do Brasil.

Na proposta de Ehri, a teoria conexionista de fases, o desenvolvimento da linguagem escrita ocorre por mudanças graduais no conhecimento e no uso das relações entre letras e sons. Ehri prefere o uso do termo fases ao invés de estágios, pois o termo estágio denota uma visão estrita de desenvolvimento, no qual uma estratégia de leitura é usada 
até ser substituída por uma mais avançada, caracterizando outro estágio (2005a). O termo fases é também mais flexível, pois permite a coexistência de várias estratégias em uma mesma fase. Embora uma predomine, é possível continuar a usar estratégias menos avançadas para a leitura de palavras novas ou pseudopalavras.

A diferença implícita entre estágios e fases é melhor discutida por Siegler (1996), quando explora as metáforas subjacentes às teorias em Psicologia do Desenvolvimento. A maioria das teorias do desenvolvimento psicológico adota, implícita ou explicitamente, um modelo de escadas, no qual as crianças se comportam de um determinado modo por um período de tempo até que progridem em direção a um modo mais avançado, como se subissem degraus em uma escada (e.g. teoria de Piaget e teoria psicogenética de Ferreiro). No entanto, Siegler argumenta que as crianças não utilizam apenas uma estratégia para resolver problemas; elas testam várias possibilidades, umas mais efetivas do que as outras em determinados momentos. Assim, o desenvolvimento é melhor caracterizado seguindo uma metáfora de ondas que se sobrepõem, em que várias estratégias coexistem, mas uma delas predomina em determinados momentos do desenvolvimento. Algumas vezes é possível retornar a estratégias menos avançadas para situações novas e logo retornar a estratégias mais avançadas. A teoria de Ehri se enquadra melhor em um modelo implícito de ondas.

Embora as teorias de estágios tenham sido muito populares, especialmente para explicar o desenvolvimento cognitivo e da linguagem, os pesquisadores atuais têm preferido modelos que expliquem as mudanças mais gradualmente (Ross, Treiman, \& Bick, 2004). A maioria das evidências em favor desses modelos vem de pesquisas sobre aritmética, em que, por exemplo, uma criança pode resolver problemas de divisão de diferentes modos obtendo o mesmo resultado. Outros estudos mostram que crianças usam várias estratégias para escrever palavras e que escolhem adaptativamente entre as estratégias, baseando-se na dificuldade das palavras (Rittle-Johnson \& Siegler, 1999).

Ehri (1997) discute que, para ler palavras, as pessoas podem se valer de predição ou adivinhação, analogia, decodificação ou leitura por memória (reconhecimento automatizado). Para escrever palavras, as pessoas podem utilizar processos muito semelhantes: memória, analogia ou invenção, que seria o correspondente da decodificação, mas que no começo, pode se assemelhar à adivinhação. Segundo Ehri (2014), o modo mais eficaz para reconhecer e produzir palavras escritas é por memória, pois a grafia já foi previamente armazenada e permite a precisão e rapidez na leitura e escrita. $\mathrm{O}$ que permite isso é um processo de formação de conexões entre as letras na grafia e os sons na pronúncia das palavras, denominado mapeamento ortográfico.

Ehri (2005a, 2005b, 2014) identificou quatro fases no desenvolvimento da leitura: pré-alfabética; alfabética parcial; alfabética completa e alfabética consolidada. Paralelamente, Ehri (1997) identificou quatro fases correspondentes no desenvolvimento da escrita: pré-comunicativa; semi-fonética, nome da letra; fonética ou fonêmica; e transicional, morfêmica, com padrões de palavras. Essas fases refletem o conhecimento e uso que os aprendizes fazem das relações entre letras e sons na direção do uso completo e convencional do sistema alfabético de escrita.

$\mathrm{Na}$ fase pré-alfabética (logográfica ou pré-comunicativa), as crianças conhecem pouco sobre o sistema de escrita e sobre como ele representa a fala, elas formam conexões visuais, como a associação entre cores e formas no logo de marcas para reconhecer seu significado. Na fase alfabética parcial(semi-fonética), as crianças acumulam mais conhecimentos sobre o sistema de escrita e passam a utilizar conexões fonológicas parciais para ler e escrever palavras, como a primeira e a última letra. $\mathrm{Na}$ fase alfabética completa (fonêmica ou fonética) as crianças são capazes de segmentar as palavras em seus fonemas constituintes e sabem as correspondências entre grafemas e fonemas, e assim podem ler e escrever todos os sons das palavras. As crianças podem tentar representar sons que não são representados ou não se ater a regras ortográficas. Na fase alfabética consolidada (ortográfica) as crianças aprendem mais sobre padrões ortográficos maiores, como sílabas, morfemas e regras ortográficas, sendo assim capazes de ler e escrever palavras polissilábicas mais rápida e corretamente.

A maioria dos estudos de Ehri discute o desenvolvimento da leitura, porém ela apresenta evidências de que a relação entre leitura e escrita é muito estreita, o que justifica sua ênfase na teoria do desenvolvimento da leitura (Ehri, 1997, 2014). Recentemente, a teoria de fases tem se consolidado apenas com os nomes refletindo o conhecimento do sistema alfabético: pré-alfabética, alfabética parcial, alfabética completa e alfabética consolidada (Ehri, 2013, 2014).

Considera-se que na Educação Infantil coexistem crianças com diferentes níveis de conhecimento de letras e de consciência fonêmica e é possível hipotetizar que essas se encontrem na fase alfabética parcial, porém em um intervalo entre as fases pré-alfabética e alfabética completa. Desse modo, objetivou-se investigar as estratégias que pré-escolares usam para escrever palavras em português do Brasil. Para tanto, hipotetizou-se que as escritas das crianças revelariam estratégias do mapeamento ortográfico utilizado por elas e que, portanto, seriam associadas à sua fase de desenvolvimento da leitura. Ainda objetivou-se analisar os tipos de escrita e de letras usadas nas diferentes palavras. Como demonstrado por Cardoso-Martins (Cardoso-Martins \& Batista, 2005), quando crianças brasileiras fazem "escritas silábicas", elas aparentam refletir mais a intenção de representar fonemas do que as sílabas. Desse modo, hipotetizou-se que as escritas revelariam mais o uso de pistas fonêmicas do que a contagem de sílabas. Além disso, os critérios usados para classificar as escritas em cada fase nem sempre são explicitados pelos pesquisadores. Assim, objetivou-se criar critérios explícitos com base em Ferreiro e Ehri, para classificar as escritas e servir como parâmetros para futuras pesquisas e práticas pedagógicas. 


\section{Método}

\section{Participantes}

Trinta e oito crianças matriculadas em classes do último ano da Educação Infantil de uma escola particular ( $n=17$ ) e uma escola pública $(n=21)$ foram incluídas na amostra. A média de idade era de 70.32 meses (DP = 3.53) e a coleta de dados foi realizada no final do semestre letivo. Somente as crianças autorizadas por meio de um Termo de Consentimento Livre e Esclarecido foram selecionadas.

\section{Procedimento}

Em uma sessão inicial com duração aproximada de 15 minutos, as crianças foram avaliadas individualmente em seu conhecimento de nomes das letras e consciência silábica e fonêmica por meio do CONFIAS (Moojen \& cols., 2007). $\mathrm{Na}$ sessão seguinte foi aplicado individualmente o Teste Matrizes Progressivas Coloridas de Raven (Angelini, Alves, Custódio, Duarte, \& Duarte, 1999) para avaliar a inteligência não-verbal. A habilidade de escrever palavras foi avaliada em uma sessão de ditado, administrada individualmente por um pesquisador treinado, com duração de 20 minutos.

\section{Instrumentos}

Tarefa de Conhecimento dos Nomes das Letras. Nesta tarefa, o pesquisador apresentou 26 cartões impressos cada com uma letra do alfabeto em maiúscula. Os cartões foram apresentados individualmente em ordem aleatória e as crianças tinham que nomear as letras. Utilizaram-se apenas letras maiúsculas, pois a observação empírica de pré-escolares sugere que há uma maior facilidade com elas do que com as minúsculas. Atribuiu-se um ponto para cada letra correta, em um escore máximo de 26 pontos.

Tarefa de Escrita de Palavras: As crianças foram solicitadas a escrever da melhor maneira possível uma série de palavras ditadas pelo pesquisador (15 palavras compostas por 2, 3 ou 4 sílabas),todas comuns ao vocabulário infantil (Pinheiro, 2006). As palavras foram: Faca, Zebra, Casa, Dedo, Sino, Girafa, Cabelo, Cavalo, Sereia, Cereja, Tartaruga, Telefone, Beterraba, Casamento, Detetive. As palavras escritas pelas crianças foram posteriormente digitadas e analisadas por meio de um processador textual que permitiu a contagem da frequência de ocorrência de grafias e letras. Letras inventadas e não identificáveis não foram contabilizadas nas análises.

Além disso, analisaram-se as estratégias utilizadas pelas crianças nas escritas. Para tanto, criaram-se categorias inspiradas na teoria psicogenética de Ferreiro (1999) e na teoria de desenvolvimento da leitura de Ehri (2014). As grafias foram categorizadas de acordo com os critérios descritos em seguida e usou-se a moda como medida para classificar as crianças na sua estratégia predominante. As escritas foram classificadas por dois juízes treinados e as dúvidas foram discutidas até que houvesse acordo.

1) Estratégia pré-alfabética: As escritas não revelam correspondência fonológica entre as letras na escrita e os sons na pronúncia. Consideraram-se garatujas ou grafias em que todas as letras não possuem correspondência fonológica com a palavra ou que usam números ou letras inventadas (e.g. FMIOAGYZ ou 6MMW).

2) Estratégia silábica sem valor sonoro: As escritas não revelam correspondência fonológica entre as letras na escrita e os sons na pronúncia, no entanto, há correspondência entre o número de letras usadas e o número de sílabas da palavra. Consideraram-se grafias em que há correspondência entre o número de letras e o número de sílabas da palavra, mas não há correspondência sonora entre todas as letras escolhidas (e.g. AE para DEDO ou OUAN para DETETIVE).

3) Estratégia silábica com valor sonoro: As escritas revelam correspondência fonológica entre as letras na escrita e os sons na pronúncia e há correspondência entre o número de letras usadas e o número de sílabas da palavra. Consideraram-se grafias em que há correspondência entre o número de letras e o número de sílabas com correspondência sonora entre todas as letras. As letras deveriam estar na ordem correta (e.g. AAUA para TARTARUGA).

4) Estratégia alfabética parcial: As escritas revelam correspondência fonológica parcial entre as letras na escrita e os sons na pronúncia e não há correspondência entre o número de letras usadas e o número de sílabas da palavra. Consideraram-se grafias em que há uma letra isolada correta (a primeira consoante ou vogal) ou grafias em que a maioria das letras estão corretas fonológica ou ortograficamente. Aceita-se que as letras estejam fora da ordem correta ou que exista troca de fonemas semelhantes(e.g. DTO para DEDO ou KBLO para CABELO). Não se consideraram escritas silábicas como alfabéticas parciais (e.g. KAO para CAVALO não é silábica, pois $\mathrm{K}$ representa dois fonemas $/ \mathrm{C} / \mathrm{+} / \mathrm{A} /$, portanto tem 4 sons e não apenas 3 - seria como CAAO).

5) Estratégia alfabética completa: As escritas revelam correspondência fonológica completa entre as letras na escrita e os sons na pronúncia. Consideraram-se grafias em que todos os sons da palavra são representados por uma letra apropriada, ainda que existam erros de ortografia ou troca de fonemas semelhantes (e.g. CAZAMENTO para CASAMENTO ou JIRAFA para GIRAFA, ou CABLO para CABELO). Aceitou-se o uso de duas letras com valores fonéticos semelhantes quando colocadas lado a lado sinalizando a dúvida entre a opção correta (e.g. CAFVALO para CAVALO).

6) Estratégia alfabética consolidada (ou ortográfica): As escritas estão convencionalmente corretas. Consideraram-se grafias corretas ortograficamente ${ }^{1}$.

1 A estratégia silábica sem valor sonoro poderia ser considerada pré-alfabética e a estratégia silábica com valor sonoro poderia ser alfabética parcial. No entanto, optou-se pela separação dessas estratégias para analisar a ocorrência do estágio silábico como proposto por Ferreiro (Ferreiro \&Teberosky, 1999). 
Prova de Consciência Fonológica - Instrumento de Avaliação Sequencial (CONFIAS). Esta prova é composta por dois conjuntos de testes. O primeiro avalia a consciência silábica por meio de 9sub-testes: síntese, segmentação, identificação de sílaba inicial, identificação de rima, produção de palavra com a sílaba dada, identificação de sílaba medial, produção de rima, exclusão, transposição. O segundo avalia a consciência fonêmica em 7sub-testes: produção de palavra que inicia com o som dado, identificação de fonema inicial, identificação de fonema final, exclusão, síntese, segmentação e transposição (Moojen \& cols., 2007). Neste estudo utilizou-se a tarefa de identificação silábica e fonêmica. Foi utilizada a pontuação bruta, contando um ponto para cada resposta correta, em um máximo de 4 pontos em cada tarefa.

Teste Matrizes Progressivas Coloridas de Raven. É composto por 36 itens divididos em três séries de 12 itens, que exigem diferentes raciocínios e estão dispostos em ordem de dificuldade crescente. Os itens são desenhos em que uma das partes está faltando e o objetivo é encontrar dentre algumas opções qual a alternativa que preenche a matriz corretamente. O teste está padronizado para a população brasileira (Angelini \& cols., 1999). Neste estudo, optou-se por utilizar a pontuação bruta.

\section{Resultados}

Com o objetivo de identificar as estratégias que pré-escolares usam para escrever palavras em português do Brasil, aplicou-se um ditado de palavras em crianças no último ano da Educação Infantil de duas escolas da cidade de São Paulo. Como medidas de controle utilizaram-se a inteligência não-verbal, a consciência silábica, a consciência fonêmica e o conhecimento de letras. Os resultados são descritos na Tabela 1. Todas as crianças tiveram resultados semelhantes e dentro da média esperada para a idade.

As escritas das crianças foram digitadas e tabuladas em Excel. As pseudoletras foram assinaladas com um asterisco e não contadas nas análises. Cada palavra foi classificada de acordo com uma das estratégias de escrita definidas com base nas propostas de Ferreiro (Ferreiro \& Teberosky, 1999) e de Ehri (2014). As estratégias de escrita e os critérios utilizados para identificá-las foram descritos na seção de métodos, atendendo a outro objetivo deste estudo, qual seja, criar critérios explícitos para classificar as escritas e servir como parâmetros para pesquisas e práticas pedagógicas.

As escritas foram classificadas em diferentes estratégias (pré-alfabética;silábica sem valor sonoro; silábica com

Tabela 1. Características, Médias (M) e Desvio Padrão (DP) das crianças.

\begin{tabular}{lll}
\hline Características & $M$ & DP \\
Sexo & Fem. = 22; Masc. $=16$ \\
Idade em meses (mín. 63 - máx. 77) & 70,32 & 3,53 \\
Conhecimento de Letras (máx. 26) & 20,61 & 4,84 \\
Consciência Silábica (máx. 4) & 2,18 & 1,16 \\
\% de Zero & $5,26 \%$ & \\
Consciência Fonêmica (máx. 4) & 1,76 & 1,24 \\
\% de Zero & $15,79 \%$ & \\
Inteligência Não-Verbal (Raven) & 15,13 & 4,51 \\
\hline
\end{tabular}

Tabela 2. Distribuição das crianças por estratégia predominante de escrita.

\begin{tabular}{lcc} 
& Frequência & \\
Estratégia Predominante & Bruta & Percentual \\
Pré-Alfabética & 9 & $23,70 \%$ \\
Silábica Sem Valor Sonoro & 0 & $0 \%$ \\
Silábica Com Valor Sonoro & 7 & $18,40 \%$ \\
Alfabética Parcial & 15 & $39,50 \%$ \\
Alfabética Completa & 1 & $2,60 \%$ \\
Alfabética Consolidada (Ortográfica) & 6 & $15,80 \%$ \\
\hline Total & 38 & $100 \%$ \\
\hline
\end{tabular}


valor sonoro; alfabética parcial;alfabética completa; alfabética consolidada)por dois juízes treinados e as dúvidas foram discutidas até que houvesse acordo. Utilizou-se a moda medida estatística para identificação do valor mais frequente da amostra - para determinar a estratégia predominante para cada criança. Dessa forma, cada criança foi classificada em uma fase do desenvolvimento da escrita, que correspondia à estratégia mais frequentemente utilizada para grafar as 15 palavras.

Na Tabela 2 está a distribuição das crianças por estratégia predominante e é possível verificar que elas variaram desde o uso predominante da estratégia pré-alfabética até a estratégia alfabética consolidada. No entanto, assim como o esperado, a estratégia mais frequente foi a alfabética parcial, considerando-se que essas crianças já conheciam letras e estavam no começo da aprendizagem da linguagem escrita. Era esperado que usassem letras para representar palavras, mas que não conseguissem fazer isso de forma completa.A estratégia alfabética parcial consiste na utilização de algumas letras para representar partes dos sons das palavras.

Uma diferença entre a proposta de Ferreiro e a proposta de Ehri consiste na importância que Ferreiro confere ao uso de estratégias silábicas no desenvolvimento da escrita, enquanto Ehri interpreta que devido ao seu conhecimento limitado, as crianças apenas passam por uma fase em que tentam representar alguns dos sons que identificam nas palavras, mas não que se concentrem na tentativa de representar as sílabas. Por esta razão consideramos separadamente estratégias silábicas com e sem valor sonoro de estratégias em que as crianças utilizavam letras para representar alguns sons, mas que não correspondiam exatamente ao número exato de sílabas.

Enquanto 15 crianças escreveram predominantemente usando estratégias alfabéticas parciais, sete crianças foram classificadas como usando predominantemente estratégias silábicas com valor sonoro. Além disso, nenhuma delas apresentou a estratégia silábica sem valor sonoro como estratégia predominante, o que sugere que essa estratégia é rapidamente superada ou apenas ocasional. Nos casos em que as crianças usavam o número de letras adequado ao número de sílabas, mas apenas uma das letras era fonologicamente correta, isso foi considerado como uma escrita alfabética parcial e não como uma escrita silábica com valor, pois para essa classificação seria necessário que todas as letras correspondentes a cada sílaba estivessem corretas. No mesmo sentido, não poderíamos classificar esse tipo de grafia como uma escrita silábica sem valor, uma vez que uma das letras era fonologicamente apropriada. Assim, optamos por considerar como uma escrita alfabética parcial, pois era uma escrita em que as crianças já revelavam a tentativa de escrever sons que detectavam na pronúncia das palavras e a contagem de sílabas não era constante nas demais escritas. Dessa forma, isso poderia ter diminuído a expressão de estratégias silábicas, que consideraria apenas o número de letras correspondentes para representar as sílabas sem considerar a apropriação fonológica. Todavia, ressaltamos que esses critérios não alteraram significativa- mente os resultados obtidos, pois mesmo quando adotamos um critério mais flexível, ainda assim nenhuma criança era classificada como usando predominantemente a estratégia silábica sem valor e não foi alterado o número de crianças que usavam predominantemente estratégias silábicas com valor. Ademais, ressaltamos que essa escolha foi proposital para manter a proposta original de Ferreiro e estabelecer uma diferença entre as estratégias silábicas (com e sem valor) e a estratégia alfabética parcial, pois em essência as três estratégias englobam escritas rudimentares e incompletas, mas as estratégias silábicas seriam uma espécie de subestratégia da estratégia alfabética parcial, nas quais o número de sílabas se tornaria significativo. Entretanto, conforme os resultados observados neste estudo, que corroboram resultados semelhantes em estudos que testam a frequência de escritas silábicas em falantes do português do Brasil (Cardoso-Martins \& Batista, 2005; Cardoso-Martins, 2013; Treiman \& cols., 2013), as hipóteses silábicas não parecem ser relevantes o suficiente para que sejam consideradas como uma etapa decisiva em classificações das estratégias utilizadas por crianças que estão aprendendo a escrever. De tal modo, a estratégia silábica sem valor poderá ser incorporada na estratégia pré-alfabética e a estratégia silábica com valor poderá ser incorporada na estratégia alfabética parcial.

Outra questão que chama a atenção é que apenas uma criança apresentou como predominante a estratégia alfabética completa, o que pode se dever à escolha das palavras utilizadas neste estudo. Como a estrutura silábica consoante-vogal (CV) foi a mais utilizada para as palavras, é possível que as crianças tenham passado rapidamente por essa estratégia na direção da estratégia ortográfica. Na Tabela 3 está a distribuição da frequência de estratégias utilizadas por palavras. Palavras mais familiares (e.g., CAVALO;CABELO) foram classificadas como alfabéticas consolidadas, porém são muito frequentes. Estudos futuros devem considerar grafias complexas e palavras de baixa frequência.

Em uma análise correlacional encontrou-se que há correlação positiva e significante entre as habilidades de consciência fonêmica e consciência silábica $(r=.56, p=$ .001), consciência silábica e estratégia de escrita $(r=.41$, $p=.011)$, consciência fonêmica e estratégia de escrita $(r=$ $.42, p=008)$ e conhecimento de letras e estratégia de escrita $(r=.51, p=.001)$. Todas as correlações são moderadas e o conhecimento de letras parece ser a habilidade que mais contribuiu para o desempenho em escrita. Ressalta-se, no entanto, que a consciência fonológica talvez tenha sido menos expressiva, poisa tarefa utilizada permitiu pouca variação e não avaliou a capacidade de segmentação, considerada como um dos melhores preditores de leitura e escrita (Ehri \& cols., 2001).

Complementando a análise de correlação, uma análise de regressão linear múltipla foi conduzida para avaliar a estratégia predominante de escrita em função do conhecimento de letras, consciência silábica e consciência fonêmica e determinar se as correlações eram independentes ou em virtude de uma terceira variável. As três variáveis 
Tabela 3. Distribuição bruta e percentual das estratégias de escrita por palavras (itens).

\begin{tabular}{|c|c|c|c|c|c|c|c|}
\hline & $\begin{array}{l}\text { Pré- } \\
\text { Alfab. }\end{array}$ & $\begin{array}{l}\text { Siláb. } \\
\text { Sem } \\
\text { Valor }\end{array}$ & $\begin{array}{l}\text { Siláb. } \\
\text { Com } \\
\text { Valor }\end{array}$ & $\begin{array}{l}\text { Alfab. } \\
\text { Parcial }\end{array}$ & $\begin{array}{l}\text { Alfab. } \\
\text { Comp. }\end{array}$ & $\begin{array}{l}\text { Alfab. } \\
\text { Consolid. } \\
\text { (Ortográf.) }\end{array}$ & Total \\
\hline Cavalo & 5 & 2 & 9 & 12 & 1 & 9 & 38 \\
\hline Girafa & 5 & 3 & 9 & 17 & 1 & 3 & 38 \\
\hline Cabelo & 7 & 1 & 9 & 13 & 0 & 8 & 38 \\
\hline Dedo & 5 & 5 & 15 & 7 & 0 & 6 & 38 \\
\hline Casamento & 7 & 2 & 1 & 24 & 2 & 2 & 38 \\
\hline Detetive & 10 & 3 & 3 & 15 & 2 & 5 & 38 \\
\hline Casa & 9 & 3 & 7 & 9 & 3 & 7 & 38 \\
\hline Tartaruga & 9 & 5 & 2 & 20 & 0 & 2 & 38 \\
\hline Faca & 7 & 8 & 8 & 7 & 1 & 7 & 38 \\
\hline Cereja & 10 & 3 & 5 & 20 & 0 & 0 & 38 \\
\hline Telefone & 8 & 2 & 2 & 19 & 3 & 4 & 38 \\
\hline Beterraba & 7 & 1 & 2 & 21 & 6 & 1 & 38 \\
\hline Zebra & 9 & 4 & 10 & 9 & 1 & 5 & 38 \\
\hline Sino & 8 & 4 & 13 & 7 & 1 & 5 & 38 \\
\hline Sereia & 7 & 3 & 6 & 16 & 5 & 1 & 38 \\
\hline Total - Bruto & 113 & 49 & 101 & 216 & 26 & 65 & 570 \\
\hline Total - \% & 19,82 & 8,60 & 17,72 & 37,89 & 4,56 & 11,40 & $100 \%$ \\
\hline
\end{tabular}

analisadas foram consideradas significativamente preditores independentes da estratégia predominante de escrita, $\mathrm{F}$ $(3,34)=6,085, R 2 a=0,292, p=0,002$. Contudo, a análise dos coeficientes de regressão e da sua significância estatística revelou que dos três preditores considerados, apenas o conhecimento de letras $(\beta=0,391, t(37)=2,595 ; p=0,01)$ é preditor significativo da estratégia predominante de escrita. A análise de coeficientes de regressão ainda revelou que a contribuição da consciência fonêmica foi maior do que a contribuição da consciência silábica para o uso de estratégias de escritas mais eficientes, mas essas contribuições não foram estatisticamente significantes.

Atendendo a outro objetivo deste estudo, que é analisar os tipos de escrita e de letras usadas, a análise qualitativa das letras utilizadas pelas crianças nas escritas demonstrou que a maioria era fonologicamente adequada. Nota-se que as trocas fonológicas ocorreram e destaca-se o uso da letra $\mathrm{H}$ no lugar na sílaba /ka/ (e.g. HLO para CAVALO, HBO para CABELO e HSA para CASA), o que sugere o uso do nome da letra "agá" pronunciado inadequadamente. Esse é um fenômeno parecido ao do caso das trocas entre as consoantes $/ \mathrm{k} / \mathrm{e} / \mathrm{g} /$, pois ambas são semelhantes no modo e ponto da articulação, diferindo apenas em relação à vibração (sonorização) das cordas vocais quando 0 ar passa pela laringe (Cardoso-Martins, 2013). Também ocorreram trocas entre letras como $\mathrm{G}$ por D como em DIRAFA para GIRAFA, em que se percebe uma intenção da criança em pronunciar o fonema /j/. Observaram-se ainda trocas como B por D, D por Te F por V.

\section{Discussão}

Neste estudo tivemos três objetivos: 1) investigar as estratégias que pré-escolares usam para escrever palavras em português do Brasil; 2) analisar os tipos de escrita e de letras usadas; e 3) criar critérios explícitos para classificar as escritas e servir como parâmetros para pesquisas e práticas pedagógicas. $O$ terceiro objetivo foi o primeiro a ser atingindo, uma vez que dele dependiam os demais objetivos.

Estabelecemos, após exaustiva análise de estudos anteriores e das propostas de Ferreiro e de Ehri, os critérios necessários para determinar as possíveis estratégias envolvidas nas tentativas de escrita das crianças. Os critérios descritos na seção de métodos permitem analisar e classificar outras escritas e não apenas as palavras usadas neste estudo, servindo como uma base para futuras pesquisas $e$ para o trabalho de professores.

Ressaltamos que esses critérios ainda poderão ser aperfeiçoados em futuros estudos. Sugerimos, por exemplo, 
que os critérios para a análise de escritas silábicas sem valor sejam incorporados na classificação de escritas pré-alfabéticas e que os critérios para a escrita silábica com valor sejam incorporados aos critérios para a estratégia alfabética parcial. Essa modificação reduz as possibilidades de classificações das escritas em pré-alfabéticas, alfabéticas parciais, alfabéticas completas e alfabéticas consolidadas (ou ortográficas), o que adere integralmente a proposta de Ehri (2014), tornando-se uma classificação mais simples e eficiente para análise do desenvolvimento da escrita em português do Brasil, sem prejuízos a caracterização desse percurso.

Endossamos nossa proposta ao discutir os demais objetivos. Ao analisar as estratégias usadas por crianças brasileiras pré-escolares quando escrevem palavras, observamos que o conhecimento de letras e a consciência fonêmica são os melhores preditores, assim como observado em outros estudos (Barrera \& Santos, 2014; Cardoso-Martins, 1995; Cardoso-Martins, 2013, Santos \& Maluf, 2010). Ainda que em nosso estudo a contribuição da consciência fonêmica não tenha sido estatisticamente significante, a análise de regressão linear múltipla mostrou que essa habilidade contribuiu independentemente mais do que a consciência silábica para o tipo de estratégia de escrita predominante.

As evidências em favor da proposta de Ferreiro sugerem que a ocorrência de um estágio silábico no desenvolvimento da linguagem escrita é um fenômeno de línguas românicas (Ferreiro \& Teberosky, 1999; Ferreiro, 1990; Pontecorvo \& Zucchermaglio, 1988; Vernon \& Ferreiro, 1999). Entretanto, os resultados do presente estudo mostram que a predominância do uso de estratégias silábicas em crianças brasileiras pré-escolares é muito pequena, comparada com o uso da estratégia de escrita alfabética parcial, na qual a interpretação é de que as crianças estão buscando representar um ou mais sons que identificam nas palavras e não necessariamente as sílabas.

Os resultados do presente estudo são coerentes com a proposta de Cardoso-Martins (Cardoso-Martins \& Batista, 2005; Cardoso-Martins, 2013) de que a escrita silábica é o resultado da compreensão da criança de que as letras representam pequenos segmentos sonoros e da sua tentativa de representar os sons que ela é capaz de detectar na pronúncia das palavras. O uso de letras correspondentes ao número de sílabas parece ocorrer devido à estrutura das palavras e à tentativa das crianças de representar os diversos sons parcialmente identificados. Além disso, como observado na Tabela 3, normalmente as escritas silábicas se relacionam com a estrutura das palavras, o que permite questionar se as crianças realmente se preocupam com a contagem de sílabas ou se a estrutura das palavras é que facilita a ocorrência de escritas silábicas.

Algumas vezes, em línguas românicas,os nomes das letras correspondem às sílabas, como por exemplo na palavra "beterraba" em que os nomes das letras B (Bê) e T (Tê) podem ser ouvidos na pronúncia das sílabas e o nome da letra pode ser utilizado como tentativa de representar os sons detectados na pronúncia, mas não necessariamente a intenção de contar sílabas, como já evidenciado em estudos anteriores (Cardoso-Martins \& Batista, 2005). Evidência adicional foi encontrada neste estudo ao mostrar que a letra $\mathrm{K}$ e $\mathrm{H}$ pode ser utilizada pelas crianças brasileiras no lugar da sílaba "cá", pois, no português do Brasil, essa sílaba corresponde ao nome da letra K. A letra H pode parecer não indicar o valor sonoro apropriado para representar "cá". No entanto, a pronúncia do nome ("agá"), para algumas crianças pequenas que ainda estão desenvolvendo a articulação da fala, soa e é pronunciado como "acá", o que fica evidente quando se observa que a mesma criança consistentemente escreveu, por exemplo: HCAO (CAVALO), HBO (CABELO), HSAO (CASAMENTO), HSA (CASA). Note-se que, no caso de HCAO, existe a dúvida entre a letra $\mathrm{C}$ ou $\mathrm{H}$ para representar a primeira sílaba. Isso foi observado em quatro crianças deste estudo.

O conjunto de evidências apresentados aqui em coerência com estudos anteriores (Cardoso-Martins \& Corrêa, 2008; Cardoso-Martins, 2013; Treiman \& cols., 2013) mostra que a predominância de estratégias de escrita silábicaé pequena no desenvolvimento da escrita de crianças falantes do Português do Brasil e reflete a compreensão de que se deve utilizar letras para representar segmentos sonoros e, em línguas românicas, as sílabas são os segmentos sonoros mais facilmente identificados.

Outrossim, os resultados corroboram a eficácia do modelo de fases de Ehri (Ehri, 2005a, 2005b, 2014) para a compreensão do desenvolvimento da linguagem escrita em português do Brasil. A divisão do desenvolvimento em fases parece ser mais apropriada do que a classificação em estágios, o que é coerente com a proposta de Ehri, pois as crianças utilizam múltiplas estratégias para escrever palavras, de acordo com os conhecimentos que possuem. Quanto mais conhecem o sistema alfabético,mais se lembram da escrita das palavras e, consequentemente, escrevem melhor, predominando, assim, o uso de estratégias mais eficientes.

A análise dos dados torna evidente que a familiaridade com algumas palavras permite às crianças escrever corretamente palavras como CASA, mesmo na fase alfabética parcial, mas são incapazes de notar que CASAMENTO partilha o mesmo início e utilizam pistas fonéticas e não morfológicas como CAZAMENTO ou ainda mais rudimentares como KZAEO. Também se destaca que, devido à estrutura das palavras utilizadas, as crianças que já estavam mais avançadas foram classificadas na fase ortográfica. Porém, talvez o mesmo não se verificasse com palavras irregulares ou complexas.

Outro aspecto importante para a discussão é o fato de que a proposta de Ferreiro foca principalmente o desenvolvimento da habilidade de escrita, enquanto que a teoria de Ehri trata, sobretudo, do desenvolvimento da habilidade de leitura. Pode-se questionar a adaptação da teoria de Ehri para a análise de estratégias de escrita. No entanto, como Ehri (1997) discute, as habilidades de leitura e de escrita são dois lados da mesma moeda. Diversos estudos mostram correlações muito fortes, acima de 70 , entre as duas habilidades. A explicação para isso é o mapeamento ortográfico, pois ambas as habilidades (ler e escrever) são governadas pelo mesmo processo de formar conexões entre grafemas 
(letras) e fonemas (sons) (Ehri, 2014). A questão fundamental que permite compreender o desenvolvimento da linguagem escrita é a aquisição do mapeamento ortográfico. As diferenças que ocorrem durante essa aprendizagem são manifestadas por diferentes estratégias que os aprendizes utilizam e que podem ser identificadas como fases.

\section{Limites, forças, implicações práticas e direções para futuros estudos}

Embora a amostra deste estudo seja pequena e restrita a apenas duas escolas, é possível estender os resultados para populações maiores de Educação Infantil considerando-se a escolha aleatória dos participantes, o que aumentou a validade externa do estudo. Além disso, as tarefas de consciência fonológica foram pouco eficazes para distinguir as crianças, pois são medidas de sensibilidade fonológica (Stanovich, 1992). Outras medidas como tarefas de segmentação são mais apropriadas para avaliar a consciência fonêmica e relacionam-se melhor com desenvolvimento da escrita (Ehri \& cols., 2001).

A operacionalização das estratégias descritas neste estudo permite que professores se beneficiem desse conhecimento para a sondagem de alunos e para uma melhor compreensão do processo de desenvolvimento da habilidade de escrita. Os critérios utilizados para a classificação das palavras fornecem indicadores apropriados para analisar as escritas das crianças falantes de português do Brasil. Futuros estudos devem considerar a ampliação das palavras da tarefa de escrita utilizada nesta investigação, considerando palavras mais complexas ou irregulares. Além disso, devem ampliar o número de participantes e acompanhar os alunos durante períodos, verificando longitudinalmente o desenvolvimento da escrita. Outros estudos podem também explorar a relação entre as habilidades de leitura e de escrita.

\section{Referências}

Alves-Martins, M. \& Silva, C. (2006). The impact of invented spelling on phonemic awareness. Learning and Instruction, 16(1), 41-56.

Angelini, A. L., Alves, I. C. B., Custódio, E. M., Duarte, W. F., \& Duarte, J. L. M. (1999). Matrizes Progressivas Coloridas de Raven: Escala Especial. São Paulo, SP: Centro Editor de Testes e Pesquisa em Psicologia.

Barrera, S. D. \& Santos, M. J. (2014). Influência da Consciência Fonológica na Aprendizagem da Leitura e Escrita: O Que Dizem as Pesquisas Brasileiras. Em J. P. de Oliveira, T. M. S. Braga, F. L. P. Viana, \& A. S. Santos (Orgs.), Alfabetização em países de língua portuguesa: pesquisa e intervenção (pp. 27-42). Curitiba: CRV.

Byrne, B. \& Fielding-Barnsley, R. (1990). Acquiring the Alphabetic Principle : A Case for Teaching Recognition of Phoneme Identity. Journal of Educational Psychology, 82(4), 805-812.
Cardoso-Martins, C. (1995). Sensitivity to Rhymes, Syllables, and Phonemes in Literacy Acquisition in Portuguese. Reading Research Quarterly, 30(4), 808-828.

Cardoso-Martins, C. (2013). Existe um Estágio Silábico no Desenvolvimento da Escrita em Português?: Evidência de Três Estudos Longitudinais. Em M. R. Maluf \& C. Cardoso-Martins (Orgs.), Alfabetização no Século XXI: Como se Aprende a Ler e a Escrever. Porto Alegres - RS: PEnso.

Cardoso-Martins, C. \& Batista, A. C. E. (2005). O conhecimento do nome das letras e o desenvolvimento da escrita: evidência de crianças falantes do português. Psicologia: Reflexão E Crítica, 18(3), 330-336.

Cardoso-Martins, C. \& Corrêa, M. F. (2008). O desenvolvimento da escrita nos anos pré-escolares : questões acerca do estágio silábico. Psicologia: Teoria e Pesquisa, 24(3), 279-286.

Ehri, L. C. (1992). Reconceptualizing the development of sight word reading and its relationship to recoding. Em P. Gough, L. C. Ehri, \& R. Treiman (Orgs.), Reading Acquisition (pp. 107-143). Hillsdale, NJ-: Erlbaum.

Ehri, L. C. (1997). Learning to read and learning to spell are one and the same, almost. Em C. Perfetti, L. Rieben, \& M. Fayol (Orgs.), Learning to Spell - Research, Theory and Practice Across Languages (pp. 237-269). Mahwah, NJ: Erlbaum.

Ehri, L. C. (1998). Grapheme-phoneme knowledge is essential for learning to read words in English. Em L. C. Ehri \& J. L. Metsala (Orgs.), Word Recognition in Beginning Literacy (pp. 3-40). Mahwah, NJ: Lawrence Erlbaum Associates Inc Publishers.

Ehri, L. C. (2005a). Development of sight word reading: Phases and findings. Em M. J. Snowling \& C. Hulme (Orgs.), Science of reading: a handbook (pp. 135-154). Oxford, UK: Blackwell Publishing.

Ehri, L. C. (2005b). Learning to Read Words: Theory, Findings, and Issues. Scientific Studies of Reading, 9(2), 167-188.

Ehri, L. C. (2013). Aquisição da habilidade de leitura de palavras e sua influência na pronúncia e na aprendizagem do vocabulário. Em M. R. Maluf \& C. Cardoso-Martins (Orgs.), Alfabetização no século XXI: Como se aprende a ler e a escrever (pp. 49-81). Porto Alegres - RS: Penso.

Ehri, L. C. (2014). Orthographic Mapping in the Acquisition of Sight Word Reading, Spelling Memory, and Vocabulary Learning. Scientific Studies of Reading, 18(1), 5-21.

Ehri, L. C., Nunes, S. R., Willows, D. M., Schuster, B. V., YaghoubZadeh, Z., \& Shanahan, T. (2001). Phonemic awareness instruction helps children learn to read: Evidence from the National Reading Panel's meta-analysis. Reading Research Quarterly, 36(3), 250287. 
Ferreiro, E. (1990). Literacy development: Psychogenesis. Em Y. Goodman (Org.), How children construct literacy: Piagetian perspectives (pp. 12-25). Newark, DE: International Reading Association.

Ferreiro, E. \& Teberosky, A. (1999). Psicogênese da Língua Escrita. Porto Alegres - RS: Penso.

Kamii, C., Long, R., Manning, M., \& Manning, G. (1990). Spelling in Kindergarten: A Constructivist Analysis Comparing SpanishSpeaking and English-Speaking Children. Journal of Research in Childhood Education, 4(2), 91-97.

Kessler, B., Pollo, T. C., Treiman, R., \& Cardoso-Martins, C. (2013). Frequency Analyses of Prephonological Spellings as Predictors of Success in Conventional Spelling. Journal of Learning Disabilities, 9(4), 317-330.

Moojen, S., Lamprecht, R., Santos, R. M., Freitas, G. M., Brodacz, R., Siqueira, M., \& Guarda, E. (2007). Consciência fonológica: instrumento de avaliação sequencial (2a ed.). São Paulo, SP : Casa do Psicólogo.

Pinheiro, Â. M. V. (2006). Leitura e escrita: Uma abordagem cognitiva. São Paulo, SP: Pleno.

Pollo, T. C., Treiman, R., \& Kessler, B. (2015). Uma revisão crítica de três perspectivas sobre o desenvolvimento da escrita. Estudos de Psicologia, 32(3), 449-459.

Pontecorvo, C. \& Zucchermaglio, C. (1988). Modes of differentiation in children's writing construction. European Journal of Psychology of Education, 3, 371-384.
Rayner, K., Foorman, B. R., Perfetti, C. a, Pesetsky, D., \& Seidenberg, M. S. (2001). How psychological science informs the teaching of reading. Psychological Science: A Journal of the American Psychological Society / APS, 2(2 Suppl), 31-74.

Rittle-Johnson, B. \& Siegler, R. S. (1999). Learning to Spell: Variability, Choice, and change in Children's Strategy Use. Child Development, 70(2), 332-348.

Ross, S., Treiman, R., \& Bick, S. (2004). Task demands and knowledge influence how children learn to read words. Cognitive Development, 19(3), 417-431.

Santos, M. J. \& Maluf, M. R. (2010). Consciência fonológica e linguagem escrita: efeitos de um programa de intervenção. Educar Em Revista, 57-71.

Siegler, R. S. (1996). Emerging Minds:The Process of Change in Children's Thinking. New York: Oxford University Press.

Stanovich, K. E. (1992). Speculation on the causes and consequences of individual differences in early reading acquisition. Em P. Gough, L. C. Ehri, \& R. Treiman (Orgs.), Reading acquisition (pp. 307342). Hillsdale, NJ: Laurence Erlbaum.

Treiman, R., Pollo, T. C., Cardoso-Martins, C., \& Kessler, B. (2013). Do young children spell words syllabically? Evidence from learners of Brazilian Portuguese. Journal of Experimental Child Psychology, 116(4), 157-162.

Vernon, S. A.\& Ferreiro, E. (1999). Writing development : A neglected variable in the consideration of phonological awareness, Harvard Educational Review, 69, 395-416.

Recebido em: 13/10/2015

Reformulado em: 25/05/2016 Aprovado em: 25/05/2016

\section{ERRATA}

No artigo:

SARGIANI, Renan de Almeida e ALBUQUERQUE, Ana. Análise das Estratégias de Escrita de

Crianças Pré-Escolares em Português do Brasil. Psicol. Esc. Educ. [online]. 2016, vol.20, n.3,

pp.591-600. ISSN 2175-3539. http://dx.doi.org/10.1590/2175-3539201502031057v

Onde se lê: Analysis of Strategies for Writing Pre-School Children in Brazilian Portuguese

Leia-se: "Analysis of Preschool Children's Spelling Strategies in Brazilian Portuguese"

\section{Sobre os autores}

Renan de Almeida Sargiani (sargiani@gmail.com)

Psicólogo, Mestre em Psicologia da Educação (PUC-SP) e Doutor em Psicologia Escolar e do Desenvolvimento Humano (IP-USP), PósDoutorando em Psicologia no Instituto de Psicologia da Universidade de São Paulo (IP-USP).

Ana Albuquerque (albuquerque.c.ana@gmail.com)

Psicóloga, Mestre em Psicologia da Educação (ISPA-IU), Pesquisadora do Instituto de Psicologia da Universidade de São Paulo. 